\title{
Challenges of the Sudden Switch from Mother Tongue Instruction to English as a Medium of Instruction
}

\author{
Shahinaz Abdullah Bukhari ${ }^{1}$ \\ ${ }^{1}$ English Language Institute, King Abdulaziz University, Jeddah, Saudi Arabia \\ Correspondence: Shahinaz Abdullah Bukhari, English Language Institute, King Abdulaziz University, Jeddah, \\ Saudi Arabia. E-mail: sbukhary@kau.edu.sa
}

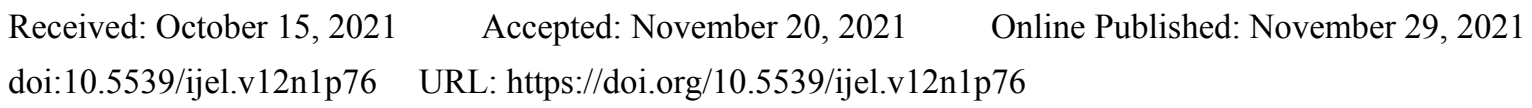

\begin{abstract}
The present study explored the challenges encountered through the transition from using the mother tongue as a medium of instruction at schools to using English as a medium of instruction at universities. Two focus groups were conducted with Saudi undergraduates and faculty members from different Saudi universities. The focus groups investigated how participants perceive this experience, what difficulties they face and how they cope. Participants expressed their preference for using English as a medium of instruction in higher education to maximise students' future and international opportunities. Participant students reported difficulties in lecture comprehension, taking notes while listening and classroom communication. Participant content lecturers reported difficulties related to students' reluctance to speak in English, lack of English terminology and insufficient lecture comprehension. Some suggestions that have been offered to overcome these challenges include the following: designing adequate trainings for content lecturers on teaching their content in English; using Arabic-English bilingualism as medium of instruction; giving emphasis to academic literacy and communication skills over the use of standard English models and enhancing the collaborative work between English language teaching practitioners and content lecturers.
\end{abstract}

Keywords: content and language integrated learning, coping techniques, English as a medium of instruction, higher education, learning and teaching difficulties

\section{Introduction}

Despite heated debates on the effects of English as a medium of instruction (EMI) on teaching-learning situation, recent EMI studies have concluded that students and faculty members are aware of the importance of giving a space for English in higher education institutions to fulfil global needs and gain access to international opportunities (Boateng, 2019; Ozer, 2020; Simbolon, 2021). Despite prolonged disputes on the issue of EMI, none has called for the use of first language (L1) as the sole medium of instruction in higher education because this language policy can impede students' future career paths and studies abroad and hinder students from gaining knowledge from up-to-date academic English resources (Airey, 2009; Al-Asal \& Smadi, 2011; Al-Bakri, 2013; Arkin, 2013; Belhiah \& Elhami, 2015; Simbolon, 2021; Suliman \& Tadros, 2011; Tamtam et al., 2013; Thogersen \& Airey, 2011).

In recent years, in the Arab world in general and the Gulf countries-including Saudi Arabia-in particular, universities have begun to adopt EMI despite the controversies on language education policies aiming to safeguard Arabic as the language of Islam, Arabic heritage and national identity (Al-Jarf, 2008; Belhiah \& Elhami, 2015; Ebad, 2014; Findlow, 2006; Lindsey, 2012; Randall \& Samimi, 2010). In Saudi public schools, students are taught entirely in Arabic with some English language classes until they get to university (Ebad, 2014). Since the early twentieth century, there has been a sudden shift into EMI in some fields, such as medicine and engineering, at Saudi public universities (Al-Jarf, 2008).

The body of EMI studies in the Arab world, especially in the Gulf, is not rich enough to provide a comprehensive understanding of EMI related issues (Al-Bakri, 2013; Ismail, 2011). Limited EMI case studies have been conducted in Saudi tertiary education, and most have used derived data such as test results and questionnaires (Yushau, 2009). They have also focused on surveying students' and faculty members' views on EMI. There is an ongoing need for an in-depth research study using instruments that are more objective than self-reporting. Dalton-Puffer (2007) and Dornyei (2007) pointed out that the most objective instrument for data 
collection in studies on bilingual education is classroom observation. Moreover, Yin (1984) asserted that direct observations are more useful than derived data in case study research on teaching practices. To extend the scope of EMI literature, this study attempts to propose an empirical research design after visiting the existing knowledge and qualitatively conducting a small-scale study.

\section{Literature Review}

\subsection{CLIL and EMI}

'Content and Language Integrated Learning' (CLIL) refers to a dual-focused educational setting that aims at teaching and learning the language of instruction and the content of the topic at the same time (Dalton-Puffer, 2007). CLIL is an acknowledged trend in immersion and bilingual education programmes (Perez-Canado, 2012). According to Coyle et al. (2010), CLIL is an integrated approach that shares some features with task-based learning, content-based instruction and subject-matter teaching; this is because CLIL uses a vehicular language in authentic interactive settings to learn content and acquire a foreign or second language (L2) without providing overt instructions as to its grammatical forms. The literature differentiates between language-led CLIL and subject-led CLIL, depending on the educational context and policies. Language-led CLIL highlights the progress of language learning, whereas subject-led CLIL excludes explicit language teaching (Coyle, 2007; Coyle et al., 2010). To overcome or minimise difficulties in EMI courses, some studies suggested CLIL approaches (e.g., Arkin, 2013; Eltoum, 2021). This suggestion implies collaboration between content and language instructors. One of the present study's objectives is to explore whether this collaboration is needed in EMI undergraduate programmes.

\subsection{Kind of English Taught in EMI and CLIL Contexts}

Jenkins (2014) categorised English usages into four groups: English as a mother tongue, English as a second language, English as a foreign language and English as a lingua franca (ELF). The term 'ELF' refers to communication in English between users of different languages or users who share L1 and choose English for contextual purposes. According to the ELF school of thought, the necessity of standard English models and English native usages for international and transcultural interactions is questioned (Baird, 2013; Bukhari, 2019; Ishikawa, 2015; Jenkins, 2014; Seidlhofer, 2005, 2013).

In academic settings, ELF can be used as a lecturing language to discuss content knowledge with users from different L1s; it can be used as a tool and not as a goal in itself (Ljosland, 2011). Based on these views, EMI is considered a subset of ELF in international higher education, including instruction and research practices (Bjorkman, 2010). ELF approaches question the necessity of English native usages for EMI settings (Kuteeva, 2014). ELF-oriented EMI aims for preparing international professionals (Jenkins, 2019). Similarly, ELF-oriented CLIL aims for a functional and transcultural as opposed to a native-like competence to prepare learners for internationalisation (Perez-Canado, 2021). One of the present study's objectives is to explore whether the use of standard English models is important in EMI undergraduate programmes; this is because the bias toward 'standardness' may exacerbate the difficulties that students and faculty members encounter in EMI settings.

Bolton and Kuteeva (2012) conducted a large-scale online survey on the use of English at a Swedish university, to which 4,524 students and 668 faculty members responded. The survey consisted of closed-ended questions, but participants were invited to write any additional relevant comments they had. The findings revealed that the use of English varies among different disciplines. It was concluded that academic literacy and communication skills in English are more important than the use of standard English models in EMI settings.

Kuteeva (2014) focused on qualitatively analysing the comments mentioned by the survey participants of Bolton and Kuteeva (2012) to explore how important it is to use standard English models in EMI contexts. The findings revealed that some participants had an urge to use the standard English models. It was concluded that the bias toward standard English models diverts attention from disciplinary-specific knowledge toward minor issues of language use. ELF-oriented EMI studies draw attention to the problems with 'one-size-fits-all' language policy in EMI settings (e.g., Baird, 2013; Kuteeva, 2014; Ljosland, 2011). This rigid policy does not allow for discipline-specific adjustments (Kuteeva \& Airey, 2014).

\subsection{Relevant Studies}

\subsubsection{Perceptions of EMI in Higher Education}

Tamtam et al. (2013) investigated faculty members' views on using Arabic only, English Only or Arabic-English bilingualism as medium of education. Interviews were conducted with 10 faculty members at two Libyan universities. All faculty members preferred the use of both Arabic and English in higher education. The participants reported that students could not comprehend the full content of EMI lectures, participate sufficiently 
in class and understand exam instructions. However, the participants agreed that the use of Arabic as a sole medium of instruction hindered students from gaining knowledge from up-to-date academic English resources and may impede students' future job opportunities. Although this qualitative study was conducted on a small scale, its conclusions are in line with the conclusions of Al-Asal and Smadi's (2011) large-scale quantitative study. Al-Asal and Smadi (2011) distributed questionnaires to 1,720 students and 241 faculty members from scientific fields at both a Syrian university where Arabic is the medium of instruction and a Jordanian university where English is the medium of instruction. It was concluded that medicine, science and technology should be taught in English to enable students to access up-to-date scientific English research.

Some previous studies' findings in an Arabic context revealed that participants are aware of the importance of English to fulfil international needs, but they prefer to use both Arabic and English in EMI classes (Belhiah \& Elhami, 2015; Tamtam et al., 2013). Al-Bakri (2013) employed an exploratory methodology with critical ethnography to explore the views of Omani college students on their learning experiences in EMI settings. The data were collected from five lecture observations and semi-structured interviews with 10 students. The qualitative analysis of the data revealed that most students were passive and did not participate in EMI lectures because of lack of understanding, low proficiency of speaking skills and lack of confidence. The findings revealed that although students expressed their preference for EMI to maximise their future opportunities, they encountered serious problems in learning their specialisations, comprehending EMI tests and responding effectively in English. It was concluded that EMI has a negative impact on the quality of education, students' disciplinary learning, content knowledge and academic performance. These conclusions agree with Arkin's (2013), Kim's (2011) and Troudi and Jendli's (2011) conclusions; they revealed that disciplinary input and exposure to English is not enough to improve students' English skills and that students face significant difficulties when they experience a sudden switch from mother tongue instruction to EMI.

Belhiah and Elhami (2015) conducted a large-scale investigation of the perceptions of 500 university students and 100 faculty members regarding the effectiveness of EMI at six universities in the United Arab Emirates. The data were collected through two surveys based on a 5-point Likert scale and two email interview questionnaires with open-ended questions. The results indicated that although students who had limited proficiency in English struggled, there was widespread agreement that EMI resulted in improved English skills. More than $50 \%$ of the participants agreed that students did not face major obstacles in understanding EMI lectures, materials and tests. Most participants preferred instruction in a combined Arabic-English medium. However, some EMI studies found that what participants reported was different from what they truly did and experienced. For example, Airey and Linder (2006) noted that students reported no learning difficulties in EMI settings, but the videotaped lecture observations and stimulated recall techniques in the interviews indicated learning problems such as inability to communicate, participate and take notes during the lectures.

\subsubsection{Difficulties of EMI}

Hellekjær (2010) investigated whether the use of EMI has a negative effect on learning and teaching by comparing lecture comprehension in L1 and English as L2. Hellekjær designed a questionnaire to identify the major variables that affect EMI lecture comprehension. Overall, 364 Norwegian students and 47 German students from five higher education institutions participated in the study. The quantitative analysis revealed a clear but nonsignificant difference between L1 and L2 lecture comprehension. A considerable number of students had difficulties in EMI lecture comprehension. The results showed that the most important factors influencing EMI lecture comprehension include lecturers' speaking speed, lecturing skills and use of unclear pronunciation and unfamiliar expressions. Other factors include students' English proficiency and difficulties in following the lecturers' line of thought. Hellekjær's (2010) conclusions align with those of Klaassen (2001); they stated that the effect of English lecturing practices on students' learning experiences was greater than that of the lecturing language itself.

Tange (2010) examined the experiences of university instructors with international teaching experience through performing a thematic analysis of a series of qualitative research interviews with 20 university instructors at three Danish universities. The findings revealed that teaching subject matter in EMI does not give content lecturers access to the same range of linguistic registers as they have in L1. Some instructors reported their inability to tell jokes, give anecdotes, tell stories or expand their illustrations with casual examples in EMI lectures. Others reported that they lowered their academic standards and offered less advanced instruction to accommodate students' knowledge and linguistic proficiency.

Through two exploratory case studies, Arkin (2013) investigated the effect of EMI on the disciplinary learning of undergraduate university students in a Turkish context, where EMI emerged suddenly at tertiary levels of 
education. The data were collected from a survey of 175 students, plus 12 lecture observations and semi-structured interviews using stimulated recall in the first case study and parallel tests in the second. The results of the quantitative and qualitative analyses revealed that, despite the pedagogical efforts of the faculty members, such as reducing the speech rate and using repetitions during lectures, students still encountered difficulties in comprehending the content. The findings showed that students are in favour of EMI because they consider it important for professional and academic purposes. However, students' disciplinary learning and their performance in tests were negatively influenced due to their limited language skills.

Ozer (2020) investigated 102 faculty members' perceptions of the challenges encountered in EMI in a state university in Turkey. The findings showed that content lecturers had difficulty finding ways of simplifying content to facilitate understanding, as well as showing a lack of improvisation and spontaneity while teaching and a need for professional development trainings on EMI. Content lecturers noted students' reluctance to speak in English, lack of English terminology and insufficient lecture comprehension. Simbolon's (2021) questionnaire investigated the current picture of EMI implementation in some Indonesian universities as one strategy to obtain international recognition. The findings showed a limited understanding of EMI practice implications in Indonesian universities.

\subsubsection{Coping Strategies}

Airey (2009) reported that students can adapt to being taught in English over a period of one year if the level of exposure to the English language is increased and when students try coping strategies such as preparing for the lesson before class, using mechanical note-taking or asking questions after class. Hellekjær (2010) confirmed that most L2 lecture comprehension difficulties are also problematic in L1 lecture comprehension. Subsequently, both studies emphasised the need to improve the quality of lecturing in both L1 and L2. These recommendations are in line with Klaassen's (2001) and Thogersen and Airey's (2011) recommendations; they noted that students can overcome EMI challenges when teachers use a condensed lecturing style, repetitions, clear pronunciations and other helpful pedagogical approaches and linguistic teaching techniques.

Tange (2010) asserted that content faculty members should complete training on EMI before they start teaching subject matters in English to fill the knowledge gap between experienced faculty members and faculty members who are new to EMI. Al-Bakri (2013) called for the use of Arabic as the medium of instruction, with the support of English for specific purposes in Omani universities, whereas Arkin (2013) recommended the use of CLIL with English for specific purposes in Turkish universities instead of EMI. In contrast, Tamtam et al. (2013) proposed the use of EMI in the early stages of education in Libyan schools to prepare future generations for the use of only English in Libyan tertiary education, whereas Belhiah and Elhami (2015) suggested hiring bilingual instructors in EMI programmes at Arabic universities to implement bilingual curricula.

Boateng (2019) discussed a series of considerations for EMI policy makers such as the following: formulating holistic language-in-education policies that view bilingualism as vital in the EMI transition phase to facilitate transfer of knowledge and skills from one language to the other and to maintain ongoing learning during the move from mother tongue to EMI; and local development of bilingual learning resources that are contextually relevant to the students and ensure that language indicators feature prominently in national and international benchmarks and assessment systems for school quality and education outcomes, particularly in education projects. Ozer (2020) concluded that collaboration between content lecturers and language lecturers in each university is of vital importance because every higher education institution has its own unique needs. Simbolon (2021) emphasised incorporating English for specific purposes in EMI programmes and the importance of stimulating collaboration between both content and English lecturers.

\section{Methods}

The main aim of this study is to investigate the broad question of whether undergraduates and faculty members face any difficulties with EMI. To this end, the following objectives are brought forward:

- $\quad$ To investigate Saudi students' and faculty members' perceptions of EMI;

- To examine the importance of following standard English models in the context of this study;

- $\quad$ To explore the difficulties that Saudi students and faculty members experience with EMI; and

- To propose suggestions for overcoming current challenges.

The research questions for this study are as follows:

- How do Saudi undergraduates perceive learning content subjects in English?

- How do Saudi faculty members perceive teaching content subjects in English? 
- How important is the use of standard English models in EMI lectures?

- What are the learning difficulties that Saudi undergraduates experience with EMI?

- What are the teaching difficulties that Saudi faculty members experience with EMI?

To answer the present study's research questions, two focus groups were conducted. The first focus group consisted of five Saudi faculty members from different Saudi universities and lasted $90 \mathrm{~min}$. The second focus group consisted of five Saudi students from different Saudi universities and lasted $70 \mathrm{~min}$. Information and consent forms were signed by all participants. The topics that were discussed in the focus groups include the following: perceptions of learning/teaching content subjects in English, importance of standard English models, difficulties and coping techniques. The focus groups were audio-recorded. In both focus groups, English and Arabic were used by the participants. In the analysis stage, Arabic utterances were translated into English. A translator was consulted to ensure the English utterances mirrored the content of the Arabic utterances. The data were then transcribed, coded and categorised into themes in relation to the present study's research questions.

\section{Findings and Discussion}

\subsection{Students' and Faculty Members' Perceptions of EMI in Tertiary Education}

All participant students and faculty members expressed a preference for EMI to maximise students' future and international opportunities:

- $\quad$ Student G: We need it in our future career.

- $\quad$ Student F: It helps us continue our studies abroad.

- $\quad$ Student Z: It's important to talk and communicate with people who are not Arabs.

- $\quad$ Student R: In English, there are interesting learning resources.

- $\quad$ Student M: So, I can work anywhere.

- $\quad$ Faculty member N: It is necessary to access updated academic resources.

- $\quad$ Faculty member D: They will need it later on for their future professional development.

- $\quad$ Faculty member T: It prepares them to be international competitors.

- $\quad$ Faculty member Y: They can get scholarships.

- $\quad$ Faculty member Q: It opens many doors for them.

4.2 Importance of Following Standard English Models in EMI Contexts

The data showed that bias toward standard English models put pressure on the participants and diverted their attention from disciplinary-specific knowledge to minor issues of language use. These findings were revealed in the comments as follows:

- Student G: When I focus on the correctness of the grammar, I lose my focus on the main information.

- $\quad$ Student F: Sometimes, I know the answer, but I don't participate in the class because I feel shy because of my accent ... I can't speak standard American and British.

- $\quad$ Student Z: I don't like it when the doctor includes grammar questions in the exam ... They should prioritise our specialisation, not English grammar.

- $\quad$ Student R: We feel uncomfortable when the teacher corrects every single word we say.

- $\quad$ Student M: The language of the book is difficult ... I can understand, but I hate it when the instructor wants me to memorise it as it is ... I want to say it in my own way.

- $\quad$ Faculty member N: I spend a long time explaining some grammatical rules, and then I can't find enough time to explain the content of the lecture.

- Faculty member D: English is not my major, and I feel guilty when I can't say something in proper English ... I mean like in standard English.

- Faculty member T: I don't know if I should deduct marks when they don't use standard English.

- $\quad$ Faculty member Y: How do we ask our students to be perfect in English while our English isn't perfect? ... It's unfair.

- $\quad$ Faculty member Q: I tried hard for many years to acquire a British standard accent so I can use it when I teach my students, but I couldn't. 


\subsection{Difficulties University Students and Faculty Members Experience in EMI Teaching/Learning Situations}

Participant students described their inability to fully comprehend, sufficiently participate in and quickly take notes during the lectures:

- $\quad$ Student G: I can't understand well when the doctor uses English only.

- Student F: We can't follow sometimes.

- Student Z: I can't participate when I don't understand.

- $\quad$ Student R: It's hard to write notes quickly in English.

- $\quad$ Student M: Sometimes I understand, but I can't say it in English ... so I don't talk.

Participant faculty members reported students' reluctance to speak in English, lack of English terminology and insufficient lecture comprehension:

- $\quad$ Faculty member N: Students stay passive in the class.

- $\quad$ Faculty member D: They don't have enough content-related terms.

- $\quad$ Faculty member T: Many students can't understand when I use only English.

- $\quad$ Faculty member Y: They don't participate enough.

- $\quad$ Faculty member Q: Their knowledge of terminologies in English needs to be developed.

\subsection{Suggestions for Overcoming EMI Difficulties in Higher Education}

The participant students preferred that instruction be conducted in a combined Arabic-English medium, and they referred to coping strategies such as preparing for the lesson before class, asking questions and recording the lectures. These findings were revealed in comments as follows:

- $\quad$ Student G: I need Arabic ... I ask questions when I don't understand.

- Student F: I bring my dictionary to class, and I translate the words I don't know.

- $\quad$ Student Z: I prepare the lesson before the class and ask my sister to translate for me.

- Student R: I record the lectures and translate them later.

- $\quad$ Student M: I ask the tutor about the meanings of the words.

The participant faculty members expressed their need for professional development trainings on EMI and collaboration between content lecturers and English language teaching practitioners. They also referred to coping strategies such as using Arabic, expanding illustrations, repetitions and reducing the speech speed. These findings were revealed in comments as follows:

- $\quad$ Faculty member N: I give more examples and details ... I use both Arabic and English ... It would be useful if an English language teacher teaches with me.

- Faculty member D: I speak slowly and I use Arabic ... I think we need special trainings on EMI.

- $\quad$ Faculty member T: We can extend explanations and provide translations ... It's a good idea to let language instructors participate in teaching with us.

- $\quad$ Faculty member Y: I repeat the same information in different ways using different words... EMI trainings will provide us with new techniques.

- Faculty member Q: We can use code-switching.

\section{Conclusion}

This study aims to explore the challenges encountered during the transition from using the mother tongue as a medium of instruction at schools to using EMI at universities. Two focus groups were conducted with five Saudi undergraduates and five Saudi faculty members from different Saudi universities. The analysis of the data revealed that all participant students and faculty members expressed their preference for EMI to maximise students' future and international opportunities. The findings showed that bias toward standard English models put pressure on students and content lectures and diverted their attention from disciplinary-specific knowledge to minor issues of language use. Furthermore, participant students noted their inability to fully comprehend, sufficiently participate in and quickly take notes during EMI lectures. Participant faculty members reported students' reluctance to speak in English, lack of English terminology and insufficient lecture comprehension. The participant students preferred instruction to be conducted in a combined Arabic-English medium, and they 
referred to coping strategies such as preparing for the lesson before class, asking questions and recording the lectures. The participant faculty members expressed their need for professional development trainings on EMI and collaboration between content lectures and English language teachers. They also referred to coping strategies such as using Arabic, expanding illustrations, repetitions and reducing the speech speed. To overcome EMI challenges and prepare international Saudi professionals, the present study suggests a switch from EMI to ELF-oriented CLIL approaches in undergraduate programmes. This switch requires collaboration between content instructors and ELF-aware language instructors.

\section{Limitations and Suggestions for Future Research}

The mini focus groups provided limited answers to the present study's research questions. Future researchers could examine the same research questions both quantitatively using large-scale surveys and qualitatively through an exploratory case study, interviews and lecture observations. The survey can be designed based on the questionnaires designed and used by Arkin (2013), Belhiah and Elhami (2015) and Hellekjær (2010). In addition to a number of closed questions, participants could be given the chance to write additional comments on the issues raised by the survey. Statistical analyses could be carried out for the data collected from the survey using SPSS software in terms of percentages, means, medians, standard deviation, additive indices, factorial analysis, significant levels, Cronbach's alpha coefficients, the Kaiser-Mayer-Olkin test, the Bartlett test, t-tests and correlations (e.g., Pearson's correlation). Following Duff's (2018) schema, researchers should start with a survey and then follow up with a relevant case study. This research design would be appropriate for addressing descriptive ('What') and explanatory ('How') research questions (Yin, 1984). The case study could take an exploratory approach because this study's research questions and its theoretical positions do not claim any prior hypotheses. A triangulation mixed methodology is recommended to conduct in-depth analyses of the students' learning experiences and the lecturers' teaching experiences. This approach allows for conducting comparisons among what participants express in the surveys, what they say in the interviews and what they do in the classroom.

Glesne (2016) and Bogdan and Biklen (1997) recommended utilising qualitative procedures when addressing a specific issue through the use of interpretive perspectives. Consequently, based on Guest et al.'s (2012) suggestion, qualitative thematic analyses could be performed on the collected data from the open-ended items of the survey and on lecture observation notes. The qualitative data could be transcribed, coded and categorised into themes based on the procedures proposed by Merriam (1998) and Saldana (2012). As proposed by Cohen et al. (2002), themes and sub-themes could be organised in relation to the research questions and the main aim of the study. According to Duff (2018) and Yin (1984), an exploratory case design is the most appropriate choice for applied linguistics studies, which aim for an in-depth understanding of a particular phenomenon in its natural settings. In EMI case studies, classroom observations provide more objective and useful views than test results and self-reported data (Dalton-Puffer, 2007; Dornyei, 2007; Yin, 1984). An exploratory enquiry could present detailed analyses and plausible interpretations of the difficulties that students and lecturers encounter in EMI teaching/learning situations. In addition to lecture observations, interviews could be conducted because the interview is the most flexible and exploratory method that can result in an in-depth understanding of personal dimensions and interviewees' experiences, which cannot be as thoroughly discovered by any other instrument (Tamtam et al., 2013).

Following Kvale's (1994) model, a series of qualitative research interviews could be performed and audio-recorded with a sample of students and faculty members. In this research design, all interviews could be exploratory in nature. In the preliminary interviews, participants could be invited to narrate their personal experiences with what works and does not work for them in EMI settings. In the main interviews, participants could then be invited to narrate episodes from teaching and learning techniques they have seen or used in EMI classrooms. Following Spradley's (1979) and Tange's (2010) analytical procedures, subsequent interviews could be conducted to find answers to ambiguous issues raised by the preliminary analysis and to check if a specific issue is confined to one participant or is of a more general nature. Topics and questions for the interviews could be designed based on lists formulated by Al-Bakri (2013), Kuteeva (2014), Tamtam et al. (2013) and Tange (2010). For sample selection, Merriam (1998) stated that nonprobability purposeful sampling is an appropriate choice for qualitative case studies.

Multiple methods could be used to investigate each issue addressed in such a study because a triangulation mixed-methods design can provide a full picture of the addressed aspects of a particular phenomenon (Silverman, 2011), assure validity, confirm the reliability of the study (Tellis, 1997) and support the conclusions of the study through the different evidence found in each method (Creswell, 2002). In this sense, emphasis is given to the dependability and consistency of the results rather than on obtaining similar results in replications (Guba \& 
Lincoln, 2003). In the absence of definitive data, trustworthiness is considered by presenting valuable knowledge, claims and judgements made by the researcher (Cohen et al., 2002; Merriam,1998; Strauss \& Corbin, 2008). Although Duff (2018) had some doubts about the generalisability of qualitative case studies, a case study is not designed to find out what is generally true, and the purposeful selection of its precise case, nonrandom sample and in-depth analyses aim to provide substantial description to the literature so that future studies can determine how closely their issues match those of the presented case study (Merriam, 1998). Stake and Trumbull's (1982) naturalistic generalisation can be attained through providing a substantial description that allows readers to make connections for themselves. In addition, Bassey's (1999) 'fuzzy generalisation' and best estimate of trustworthiness approach may be adopted to make the knowledge claims more explicit by giving professional judgements and generalisations in broad terms about what may be rather than what definitely is.

\section{References}

Airey, J. (2009). Science, language, and literacy: Case studies of learning in Swedish university physics. Doctoral dissertation, Appsala University. Sweden.

Airey, J., \& Linder, C. (2006). Language and the experience of learning university physics in Sweden. European Journal of Physics, 27(3), 553-560. https://doi.org/10.1088/0143-0807/27/3/009

Al-Asal, M., \& Smadi, O. (2011). The effect of the language of instruction on university participants' acquisition of scientific terms. European Scientific Journal. 52(1), 5-28.

Al-Bakri, S. (2013). Problematizing English medium instruction in Oman. International Journal of Bilingual and Multilingual Teachers of English, 207(1172), 1-15.

Al-Jarf, R. (2008). The impact of English as an international language (EIL) upon Arabic in Saudi Arabia. Asian EFL Journal, 10(4). 193-210.

Arkin, I. (2013). English-medium instruction in higher education: A case study in a Turkish university context. Doctoral dissertation, Eastern Mediterranean University. Northern Cyprus.

Baird, R. (2013). Investigating perceptions of master's students on English-as-a-medium-of-instruction programmes in East Asia. Doctoral dissertation, University of Southampton. United Kingdom.

Bassey, M. (1999). Case study research in educational settings. Maidenhead: Open University Press.

Belhiah, H., \& Elhami, M. (2015). English as a medium of instruction in the Gulf: When students and teachers speak. Language Policy, 14(1), 3-23. https://doi.org/10.1007/s10993-014-9336-9

Bjorkman, B. (2010). So you think you can ELF: English as a lingua franca as the medium of instruction. Hermes-Journal of Language and Communication in Business, 45, 77-96. https://doi.org/10.7146/hjlcb.v23i45.97348

Boateng, P. (2019). Managing transitions from mother tongue instruction to English as the medium instruction. K4D help disk reports. Retrieved October 26, 2021, from https://assets.publishing.service.gov.uk/media/5c6e891240f0b647b45f6cae/520_Mother_Tongue_Language _Instruction_002_pdf

Bogdan, R., \& Biklen, S. (1997). Qualitative research for education. Boston: Allyn \& Bacon.

Bolton, K., \& Kuteeva, M. (2012). English as an academic language at a Swedish university: Parallel language use and the 'threat' of English. Journal of Multilingual and Multicultural Development, 33(5), 429-447. https://doi.org/10.1080/01434632.2012.670241

Bukhari, S. (2019). Complexity theory approaches to the interrelationships between Saudis' perceptions of English and their reported practices of English. Doctoral dissertation, University of Southampton. United Kingdom.

Cohen, L., Manion, L., \& Morrison, K. (2002). Research methods in education. London: Routledge. https://doi.org/10.4324/9780203224342

Coyle, D. (2007). Content and language integrated learning: Towards a connected research agenda for CLIL pedagogies. International Journal of Bilingual Education and Bilingualism, 10(5), 543-562. https://doi.org/10.2167/beb459.0

Coyle, D., Hood, P., \& Marsh, D. (2010). CLIL. Content and language integrated learning. Cambridge: Cambridge University Press.

Creswell, J. (2002). Educational research: Planning, conducting, and evaluating quantitative and qualitative 
research. Upper Saddle River: Person Education.

Dalton-Puffer, C. (2007). Discourse in content and language integrated learning (CLIL) classrooms. Amsterdam: John Benjamins. https://doi.org/10.1075/11lt.20

Dornyei, Z. (2007). Research methods in applied linguistics. Oxford: Oxford university press.

Duff, P. (2018). Case study research in applied linguistics. New York: Routledge. https://doi.org/10.4324/9780203827147

Ebad, R. (2014). The role and impact of English as a language and a medium of instruction in Saudi higher education institutions: Students-instructors perspective. Studies in English Language Teaching, 2(2), 140-148. https://doi.org/10.22158/selt.v2n2p140

Eltoum, R. A. (2021). Content and language integrated learning (CLIL) and the linguistic difficulties of Saudi students learning algebra. Journal of Immersion and Content-Based Language Education. Retrieved November 28, 2012, from https://www.jbe-platform.com/content/journals/10.1075/jicb.20009.elt

Findlow, S. (2006). Higher education and linguistic dualism in the Arab Gulf. British Journal of Sociology of Education, 27(1), 19-36. https://doi.org/10.1080/01425690500376754

Glesne, C. (2016). Becoming qualitative researchers: An introduction. New Jersey: Pearson.

Guba, E., \& Lincoln, Y. (2003). Fourth generation evaluation. Newbury Park: Sage.

Guest, G., MacQueen, K., \& Namey, E. (2012). Applied thematic analysis. Los Angeles: Sage. https://doi.org/10.4135/9781483384436

Hellekjær, G. (2010). Lecture comprehension in English-medium higher education. HERMES-Journal of Language and Communication in Business, 45, 11-34. https://doi.org/10.7146/hjlcb.v23i45.97343

Ishikawa, T. (2015). Academic rigour in criticising English as a Lingua Franca. Englishes in Practice, 2(2), 39-48. https://doi.org/10.1515/eip-2015-0002

Ismail, M. (2011). Language planning in Oman: Evaluating linguistic and sociolinguistic fallacies. Doctoral dissertation, Newcastle University. United Kingdom.

Jenkins, J. (2014). Global Englishes: A resource book for students. London: Routledge. https://doi.org/10.4324/9781315761596

Jenkins, J. (2019). English medium instruction in higher education: The role of English as lingua franca. In X. Gao (Ed.), Second handbook of English language teaching (pp. 1-18). Cham: Springer. https://doi.org/10.1007/978-3-319-58542-0_7-1

Kim, K. (2011). Korean professor and student perceptions of the efficacy of English-medium instruction. Linguistic Research, 28(3), 711-741. https://doi.org/10.17250/khisli.28.3.201112.013

Klaassen, R. (2001). The international university curriculum: Challenges in English-medium engineering education. Doctoral dissertation, Delft University of Technology. Netherlands.

Kuteeva, M. (2014). The parallel language use of Swedish and English: the question of 'nativeness' in university policies and practices. Journal of Multilingual and Multicultural Development, 35(4), 332-344. https://doi.org/10.1080/01434632.2013.874432

Kuteeva, M., \& Airey, J. (2014). Disciplinary differences in the use of English in higher education: Reflections on recent language policy developments. Higher Education, 67(5), 533-549. https://doi.org/10.1007/s10734-013-9660-6

Kvale, S. (1994). Interviews: An introduction to qualitative research interviewing. Thousand Oaks: Sage. https://doi.org/10.1163/156916294X00016

Lindsey, U. (2012). Debate arises at Qatar U. over decision to teach mainly in Arabic. The Chronicle of Higher Education. Retrieved May 5, 2020, from https://www.chronicle.com/article/debate-arises-at-qatar-u-over-decision-to-teach-mainly-in-arabic/

Ljosland, R. (2011). English as an academic lingua franca: Language policies and multilingual practices in a Norwegian university. Journal of Pragmatics, 43(4), 991-1004. https://doi.org/10.1016/j.pragma.2010.08.007

Merriam, S. (1998). Qualitative research and case study applications in education. San Francisco: Jossey-Bass.

Ozer, O. (2020). Lecturers' experiences with English-medium instruction in a state university in Turkey: 
Practices and challenges. Issues in Educational Research, 30(2), 612-634.

Perez-Canado, M. (2012). CLIL research in Europe: Past, present, and future. International Journal of Bilingual Education and Bilingualism, 15(3), 315-341. https://doi.org/10.1080/13670050.2011.630064

Perez-Canado, M. (2021). CLIL and ELF: Friends or foes?. In M. Perez-Canado (Ed.), Content and language integrated learning in monolingual settings: New insights from the Spanish context (pp. 31-51). Cham: Springer Nature.

Randall, M., \& Samimi, M. (2010). The status of English in Dubai. English Today, 26(1), 43-50. https://doi.org/10.1017/S0266078409990617

Saldana, J. (2012). The coding manual for qualitative researchers. London: Sage.

Seidlhofer, B. (2005). Key concepts in ELT: English as lingua franca. ELT Journal, 59(4), 339-341.

Seidlhofer, B. (2013). Understanding English as a lingua franca. Oxford: Oxford University Press. https://doi.org/10.1002/9781405198431.wbeal0243

Silverman, D. (2011). Doing qualitative research. Los Angeles: Sage.

Simbolon, N. (2021). English Medium Instruction (EMI) practice: Higher education internationalization in Indonesia. Englisia. Journal of Language, Education, and Humanities, 8(2), 72-83.

Spradley, J. (1979). The ethnographic interview. New York: Holt, Rinehart \& Winston.

Stake, R., \& Trumbull, D. (1982). Naturalistic generalizations. Review Journal of Philosophy and Social Science, $7(1), 1-12$.

Strauss, A., \& Corbin, J. (2008). Basics of qualitative research. Los Angeles; London; New Delhi: Sage.

Suliman, W., \& Tadros, A. (2011). Nursing students coping with English as a foreign language medium of instruction. Nurse Education Today, 31(4), 402-407. https://doi.org/10.1016/j.nedt.2010.07.014

Tamtam, A., Gallagher, F., Naher, S., \& Olabi, A. (2013). The impact of language of instruction on quality of science and engineering education in Libya: Qualitative study of faculty members. European Scientific Journal, 9(31), 1-18.

Tange, H. (2010). Caught in the Tower of Babel: University lecturers' experiences with internationalisation. Language and Intercultural Communication, 10(2), 137-149. https://doi.org/10.1080/14708470903342138

Tellis, W. (1997). Application of a case study methodology. The Qualitative Report, 3(3), 1-19. https://doi.org/10.46743/2160-3715/1997.2015

Thogersen, J., \& Airey, J. (2011). Lecturing undergraduate science in Danish and in English: A comparison of speaking rate and rhetorical style. English for Specific Purposes, 30(3), 209-221. https://doi.org/10.1016/j.esp.2011.01.002

Troudi S., \& Jendli, A. (2011). Emirati students experiences of English as a medium of instruction. In A. Al-Issa, \& L. Dahan (Eds.), Global English and Arabic: Issues of language, culture and identify (pp. 23-48). Oxford: Peter Lang.

Yin, R. (1984). Case study research: Design and methods. Thousand Oaks: Sage.

Yushau, B. (2009). Mathematics and language: issues among bilingual Arabs in English medium universities. International Journal of Mathematical Education in Science and Technology, 40(7), 915-926. https://doi.org/10.1080/00207390903223846

\section{Copyrights}

Copyright for this article is retained by the author, with first publication rights granted to the journal.

This is an open-access article distributed under the terms and conditions of the Creative Commons Attribution license (http://creativecommons.org/licenses/by/4.0/). 